\title{
Secondary Origin of the Radial Fabric in Stalactitic Carbonate
}

\author{
Paul L. Broughton*
}

SUMMARY

'The growth surfaces of most stalactites are interpreted as numerous syntaxial overgrowth crystallites. These coalesce immediately behind the growth surface, often trapping portions of the water film as fluid-filled cavities. The fluid inclusions represent former inter-crystallite spaces and characterize the widely misinterpreted "growth ring".

Complete crystallite coalescence generates inclusions-free calcite, whereas inhibition of lateral coalescence of the overgrowth crystallites generates layers of acicular calcite. It is generally only during periods of cave flooding that the crystallites merge and overgrow each other and precipitation eventually occurs upon large. planar crystal faces. Stalactitic carbonate growth is secondary, from a multi-crystalline precursor that is, in a sense, a large skeletal crystal. The precursor crystallites are in lattice continuity with the substrate and with adjacent crystallites. Crystal boundaries arise from lateral lattice mismatch on the curved growth surface. It is not competitive growth as the secondary columnar crystals do not interfere with each other.

\section{INTRODUCTION}

The petrology of stalactitic carbonates has only recently received significant attention, and until recently few concepts have emerged concerning growth processes active during formation of these materials. With the exception of early work by Prinz (1906) and recent studies of Kirchmayer (1964) and Hahne et. al. (1968) on cave pearls, and Folk and Assereto (1976) on a single specimen of a flowstone, most work has been

* Present Address: Home Oil Company, 1700 Home Oil Tower, 324 - 8 Avenue. S.W., Calgary, Alberta, Canada 
concerned with external form, or with mineralogical and chemical aspects or local to regional distribution. When such crystal fabrics have been examined specifically, the interpretations have often been somewhat simplistic (Moore, 1962). This deficiency was partially remedied with the recent Kendall and Broughton (1978) theory on the origin of fabrics in speleothems by precursor syntaxial crystallite overgrowths. This paper is a modification of that collaboration and reviews this theory and its significance for the speleologically-oriented readers. This paper elucidates a theory of stalactitic carbonate growth that is considered to be applicable to the commonest type of calcite mosaic in speleothems. This is composed of columnar crystals radiating about an axis, together with associated growth layers of acicular or fibrous calcite and layers that resemble the "coconut-meat» calcites of Folk and Assereto (1976) but which are composed of length-fast calcite crystals (Kendall and Broughton, 1977). These various types of stalactitic calcite fabrics grade into each other and may be ascribed to a common genesis.

\section{MATERIALS}

This study is based on a couple of hundred petrographic sections cut from almost an equivalent number of stalactites and stalagmites. Many of these were examined by scanning electron microscope techniques (S.E.M.). Our samples lack locations or are pcorly located, and much of the material has been secured from numerous museum collections, individual contributions and removed from caves ahead of quarrying operations. This research is suggested to be independent of locality data, and for this reason they have not been given in the figure descriptions.

\section{NOMENCLATURE}

Some ambiguity persists regarding the terms used to describe crystal forms. The following discussion elucidates how several terms are used in this paper. Acicular is used to describe materials composed of needle-like, markedly elongate and pointed crystals less than 5 microns wide. This term is used regardless of the mode of packing, and includes fabrics often referred to as fibrous (clcsely packed acicular) by many authors. Columnar is used to describe crystals that are elongate and wider than 10 microns. Such crysals are described as fibrous by many authors (Folk terminology). Subcrystal has two meanings. It can refer to a crystal subdivision, partially synonymous with domain, usually recognized optically by its uniform 
extinction. Subcrystal is used in this sense for this paper. The term also can mean material deposited on a portion of the crystal's growth surface that is separated from other parts by having discrete crystallite faces. These commonly give rise to the domains of the first meaning, but this is not the case in stalactitic carbonates. In this paper, the second type of subcrystals is referred to as syntaxial overgrcwth crystallites.

\section{THE SECONDARY NATURE OF COLUMNAR CRYSTALS}

\section{Tho Argument Against Primary Competitive Growth Fabrics}

The traditionally accepted origin of stalactite growth was summarized by Prinz (1906), was reiterated and popularized by Moore (1962) and is to be found in most textbooks that mention the subject. This theory states that stalactite growth commences when dripping water deposits carbonate as a tubular (the soda-straw) structure. Water flowing as a film over the exterior surface deposits a new type of calcite fabric which constructs the familiar conical or candle-shaped form. This outer coating is most ccmmonly composed of elongate calcite crystals which, in sections cut normal to the stactite long axis, have their long axes radially disposed. Former growth surfaces are discernible by bands that contain abundant impurities. Such bands are commonly believed to record cessations or episodes of slower stalactite growth. Moore (1962) suggested that following interruption of growth, innumerable tiny randomly-oriented seed crystals are depcsited on the new growth surface. Competitive growth between these crystals was propcsed to result in the formation of the familiar radial-columnar crystal mosaics in stalactites and stalagmites. The resumption of calcite precipitation would favour those small crystals having their c-axes criented normal to the growth surfaces, and would eventually dominate as elongate crystals.

This paper proposes that normal stalactitic carbonate growth is not by competitive crystal growth, but alternately, a secondary fabric that suggests a very different origin. If the radial-columnar mosaics in stalactites result from a process of competitive crystal growth, then these mosaics should preserve evidence of this growth surface. All crystals, large and small, are columnar and have their axes of elongation and optic axes more or less normal to the growth surfaces. Most stalactites lack any region where competitive crystal growth can be inferred to have occurred, and there is no region where differently-oriented crystals can be seen to have competed for growth space 


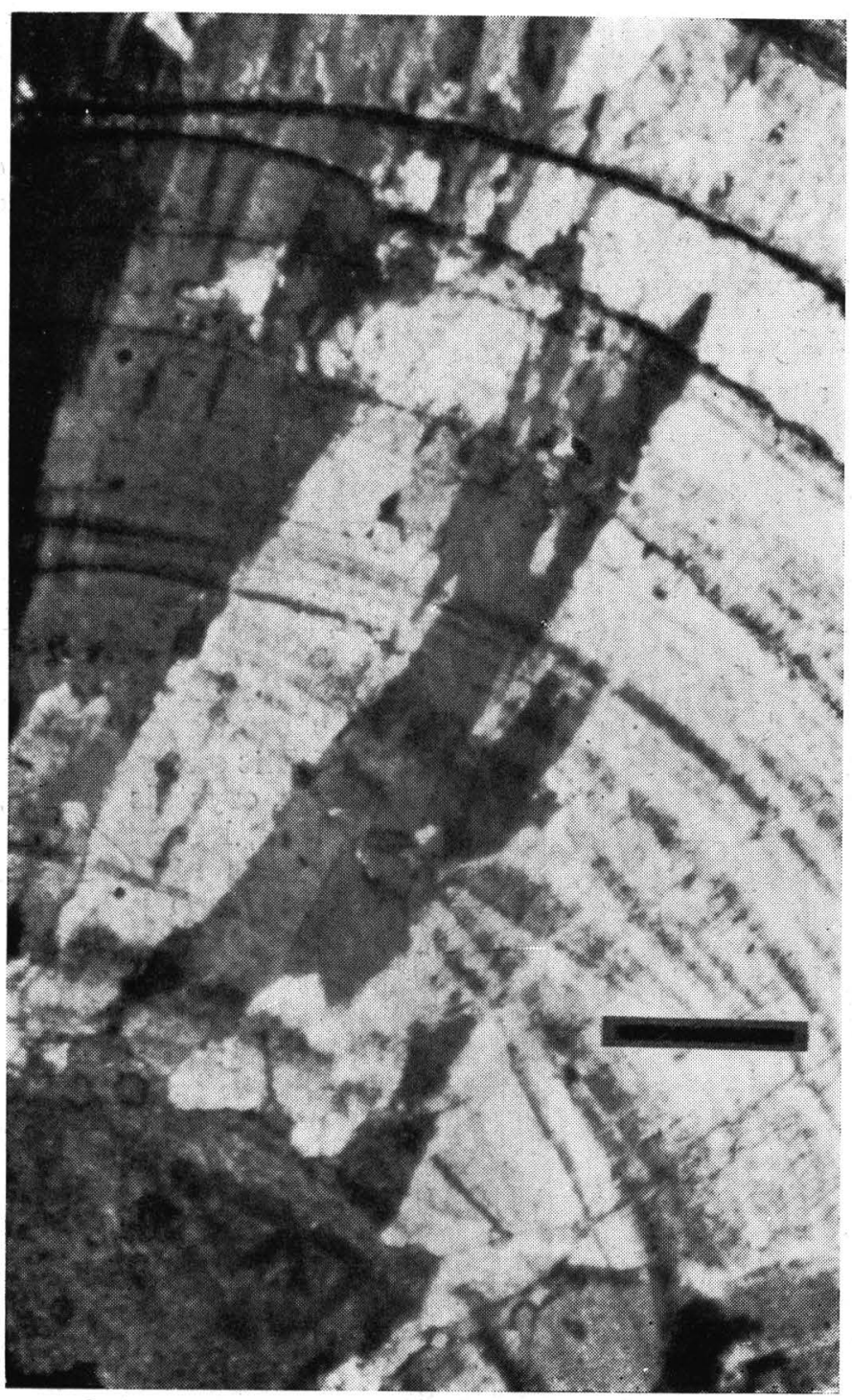

Fig. 1 - Portion of a stalactite viewied in cross-section with cross-polarized light. The partially extinguished crystals are part of the central axis, the "soda-straw". All other crystals comprise a portion of the radial fabric, and are elongated such that no zone displays a fabric indicative of competitive crystal growth. Scale is $0,5 \mathrm{~mm}$. 


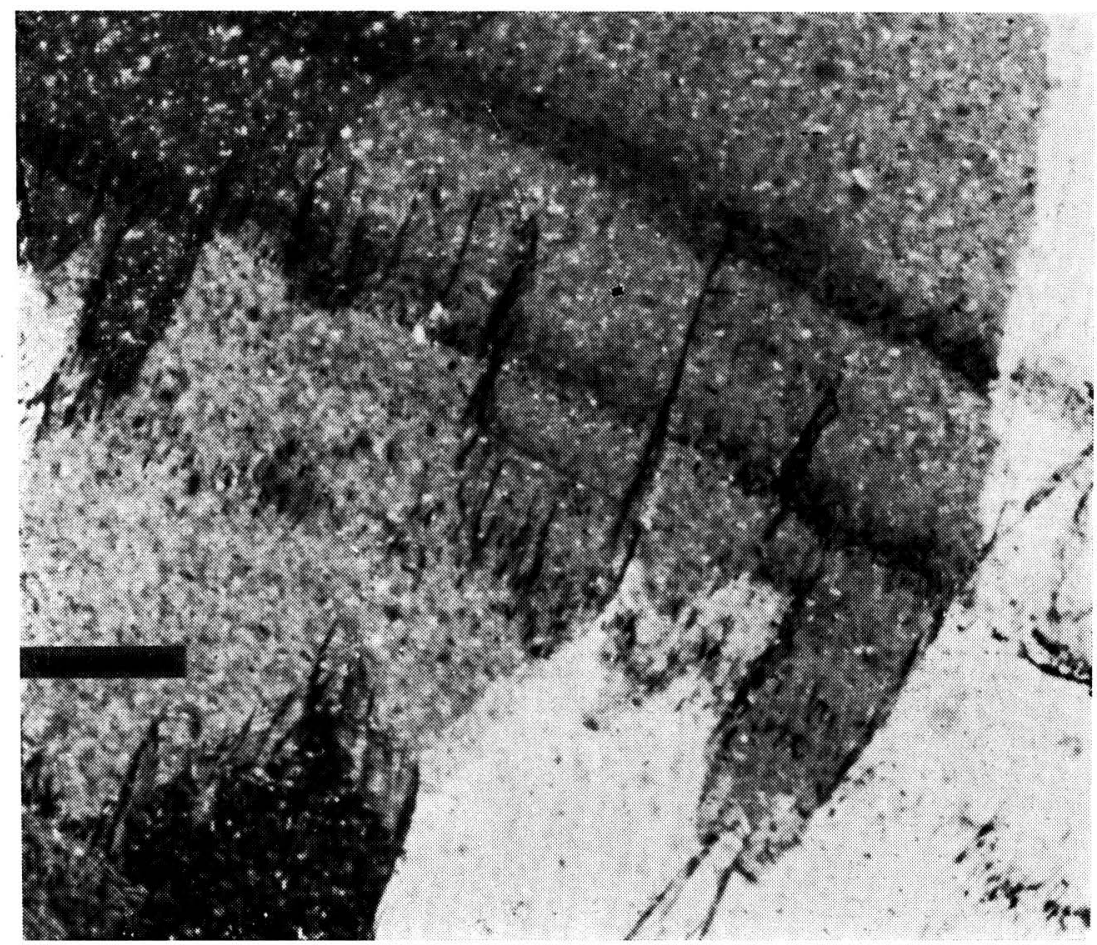

Fig. 2 - Host crystals with irreguiar jagged boundaries exhibiting pseudopleochroic and inclusion defined growth layers cross-polarized light. Scale is $0,5 \mathrm{~mm}$. The boundary is not related to the crystallographic orientation, which argues against competitive growth.

(Fig. 1). Also, crystal boundaries and shapes differ from those drusy calcite cements that are a consequence of competitive growth. In these para-axial cements, crystals in contact with each other meet along planes (compromise boundaries of Buckley, 1951). As each crystal grows, these planes enlarge and their orientations are dependent upon the growth rates of the two crystal faces that are growing towards and against each other and the angle between them (Bathurst, 1971, p. 422-423).

Boundaries in competitive growth limestone cements will be commonly inclined with respect to the substrate surface because the crystal with the faster-growing or more favourablyoriented face adjacent to the common boundary expands at the expense of the less-favoured crystal. The smaller the difference in crystailographic orientation between adjacent crystals, the 
less inclined to the radial axis will be their compromise boundary plane. Thus, bcundaries between similarly or equally favourable orientations will tend to be normal to the substrate surface.

This geometric relationship between crystal orientations (caxes) and their boundaries is commonly absent in stalactitic carbcnate mosaics. Exceptions are discussed in the next section.

Boundaries in stalactites have the following characteristics: (1) the crystal boundaries are commonly jagged and thus unlikely to be simple compromise boundaries, (2) these boundaries commonly exhibit complex and irregular re-entrants (3) crystals may be encroached upon by their neighbors, incommensurate with differences in neighbouring crystal orientation, over portions of their length but elsewhere may widen at the expense of the same neighbours. See Figures 1 and 2. Boundaries between columnar crystals having equally-favoured crystallographic orientations should be more or less normal to earlier growth surfaces of the stalactite if competitive, but it is commonly found that boundaries between such crystals are markedly inclined by more than $25^{\circ}$ to the growth layering. In thin section, this may generate wedge-shaped crystals quite unlike any growth habit in «normal» para-axial cements.

\section{Competitive Crystal Growth Fabrics}

Some growth layers, a minority in most stalactites, are composed of crystals with planar boundaries. Such layers often display additional fabrics suggestive of the Moore (1962) competitive crystal growth mechanism: decreasing number of crystals and an increasing perfection of the preferred dimensional and crystallographic orientations of crystals away from the layer's origin. Growth layers of this type commonly overlie zones containing abundant and thick impurities and evidently were seeded from these former growth surfaces in the manner suggested by Moore (1962). Crystals in layers exhibiting such drusy fabrics are, however, commonly in lattice continuity with apparent primary and secondary fabrics. This passage between parts of crystals which may be considered a possible neomorphic origin and crystals in younger growth layers whose lattice exhibits secondary characteristics would develop as a consequence of the growth mechanism of the crystals rather than result from neomorphism. It is difficult to explain why neomorphism should be confined to discrete growth layers and still have the component crystals in lattice continuity with unneomorphic fabric. 


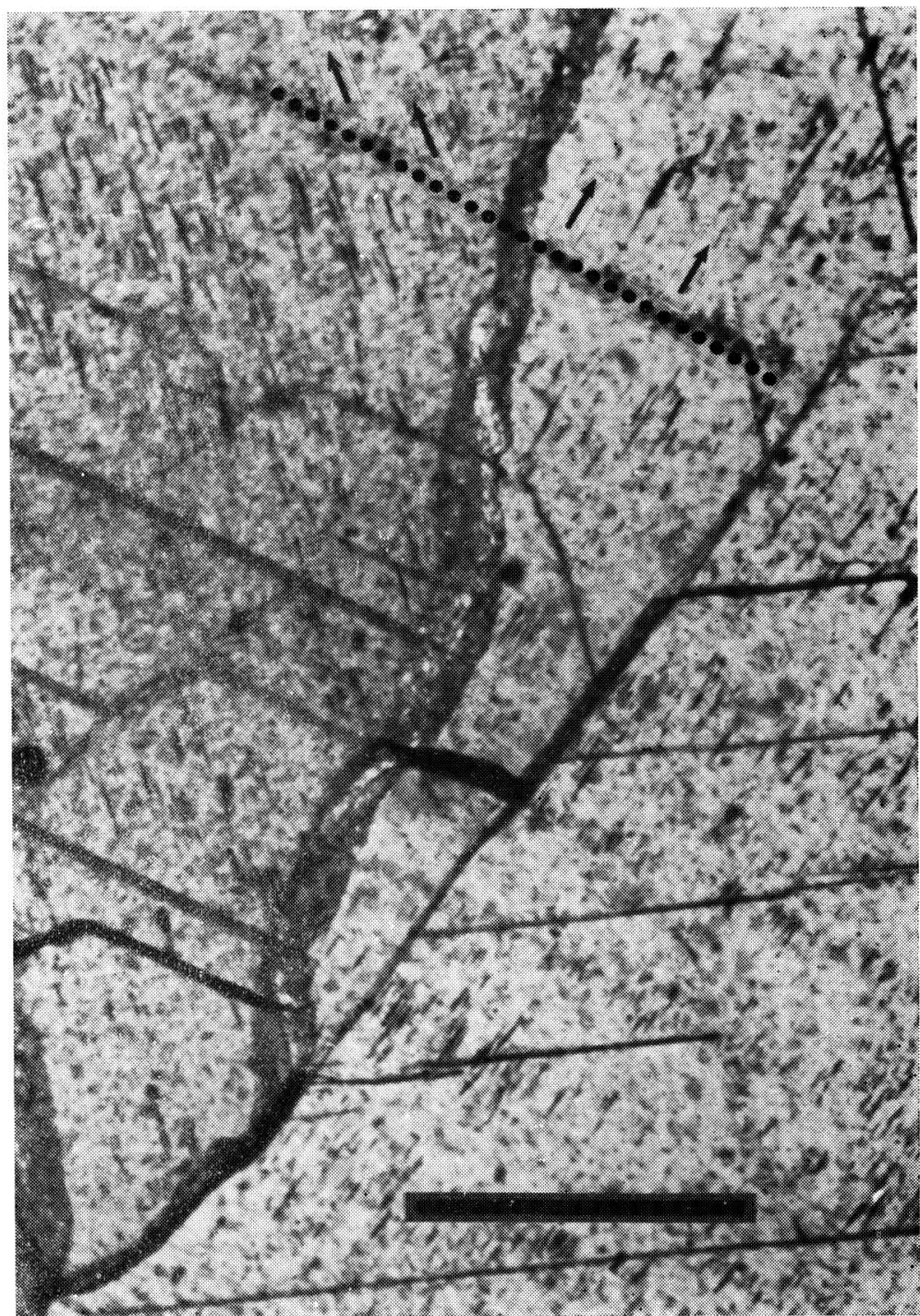

Fig. 3 - Detail of an irregular boundary between two crystals with different crystallographic orientations that each contain uniquely-oriented linear inclusions parallel to the optic axis in the host crystal. A single growth layer is delineated by the dotted line, whereon the left hand crystal has linear inclusions oriented obliquely to the growth surfaces and the right hand crystal's are normal. Plane polarized light. Scale is $0,5 \mathrm{~mm}$. 


\section{GROWTH LAYERING AND INCLUSION PATTERNS}

Inclusions are trapped by the advancing growth surface and variations in either the supply or the rate of impurity absorption give rise to variations in impurity concentration which define the growth layering. Inclusions may be so abundant that they appear to have impeded crystal growth to cause discontinuities in the crystal mosaic.

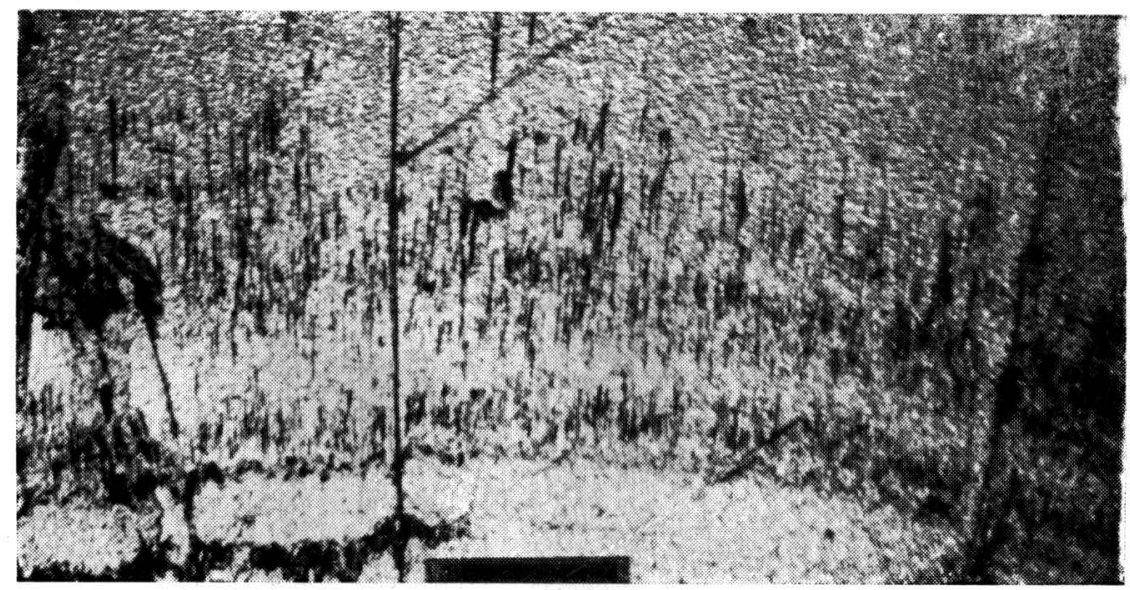

Fig. 4 - Growth layers defined by linear inclusions (type 1) which exhibit slight but gradual changes in orientation across the crystals which parallels a similar variations in the optic axis orientations. The lattice continuity between the lateral crystallite coalescence is essetially continuous across the slightly curved growth surface. Crosspolarized light. Scale is $0.5 \mathrm{~mm}$.

Inclusions and the patterns they make are the most important evidence for interpreting the origin and growth of stalactitic carbonate. There are six types of growth layering recognized:

Type 1. layers are smooth curves, each composed of closelyspaced, parallel to sub-parallel, linear inclusions. Each lineation parallels the optic axis orientation of the host crystal, even when this is oblique to the growth surface. Each thus possess its own individual orientation of inclusions (Figs. 3, 4 and 5).

Type 2. layers are smooth curves, like type 1, but are defined as pseudo-pleochroic brown bands originating as inclusion 


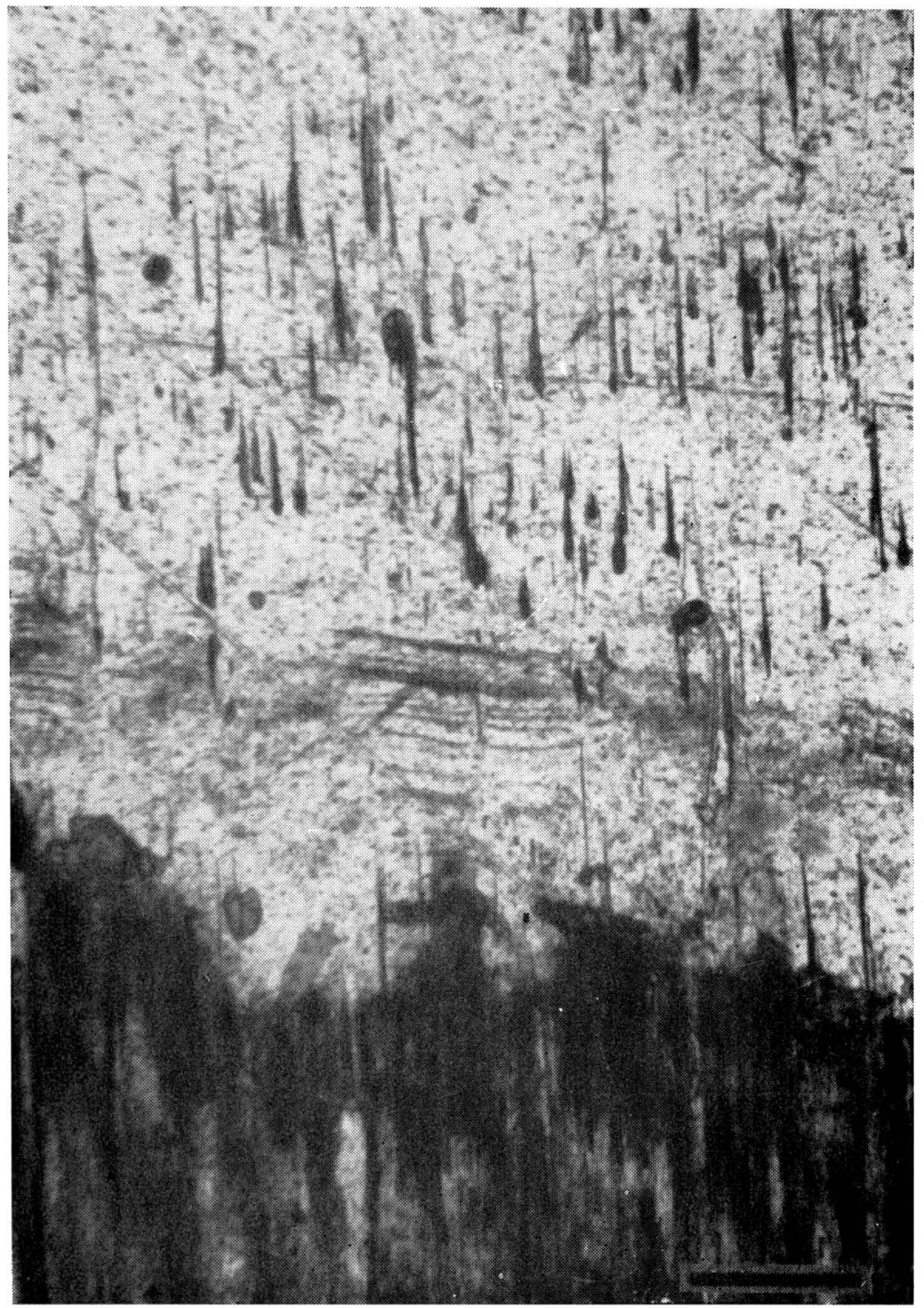

Fig. 5 - Different types of growth layers in close association. There are large, thorn-shaped inclusion defined layers, pseudo-pleochroic layers with a laminated-like banded appearance and concentration of abundant impurities that dominate the lower portion of the figure. Plane polarized light. Scale is $0.5 \mathrm{~mm}$. 


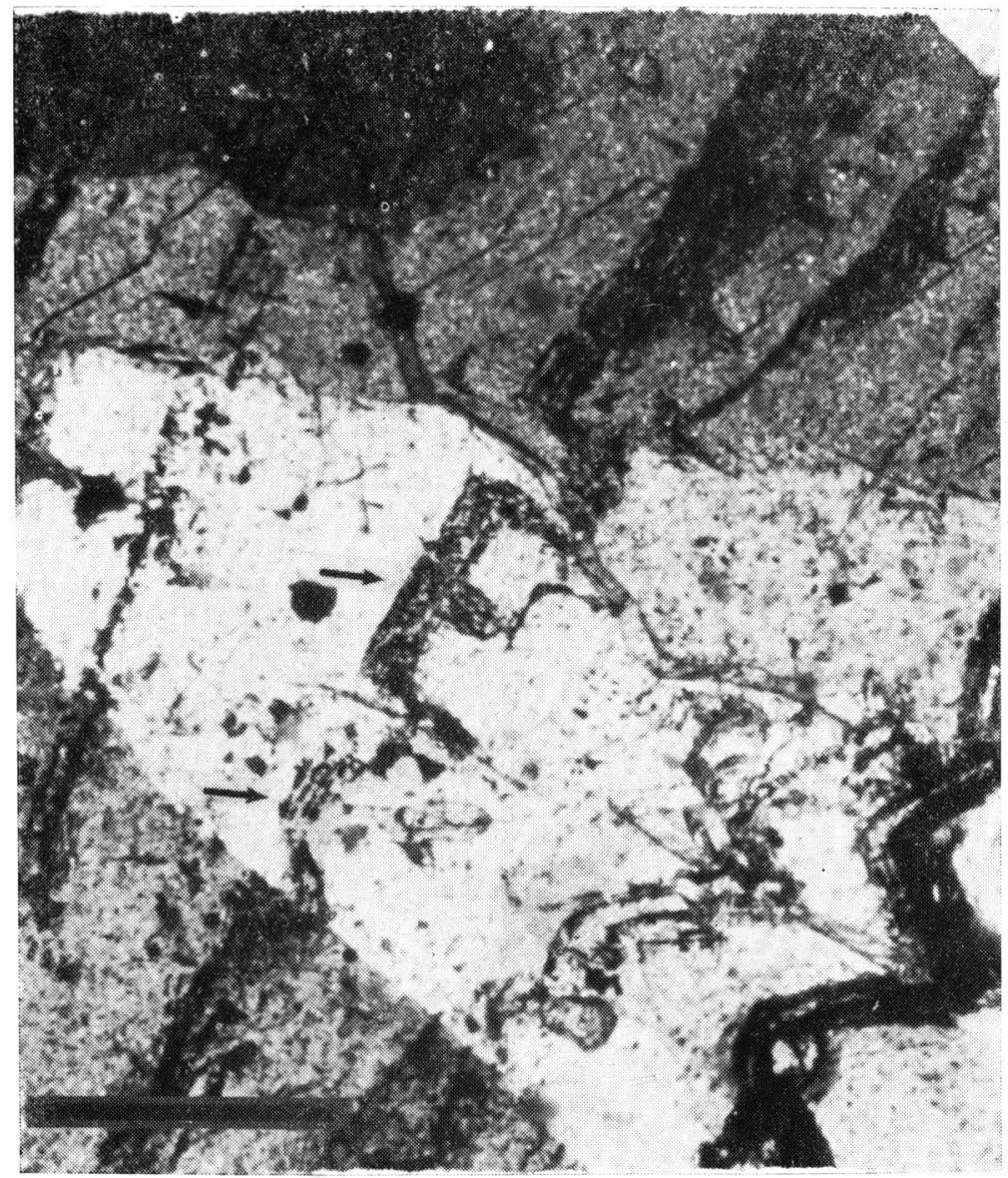

Fig. 6 - Pseudopleochroic calcite growth layers that delineate former positions of "truncated" calcite crystal terminations within a larger host crystal. Such quadratic terminations are not true crystal faces but occur as small segments of an otherwise smoothly curved growth surface. Crystal growth can only proceed up to the surface of the thin fluid film and true terminal crystal faces are not normally developed. Cross-polarized light. Scale is $0.5 \mathrm{~mm}$. 
concentrations which are not separately resolvable by optical means (Figs. 2 and 5).

Type 3. layers are also defined by extremely fine inclusions but insteed of being smocth, define former positions of rhombohedral crystal faces. Such terminations may be complete or incomplete where the growth layers combine features of layers tjpes 2 and 3. Such growth surfaces are sinooth but periodically divide into segments by re-entrants that represent parts of crysial terminations. Kendall and Broughton (1977) reject the presence of these termination traces as the sole criterion for identification of aragonite replacements. Some inclusion-defined crystal boundaries are not now ass'ociated with crystal boundaries. See Figures 6, 7 and 8 .

Type 4. layers also define former calcite terminations but are themselves defined by linear inclusions.

Type 5. layers are distinguished by occurrences of large quantities of impurities. The crystal fabrics are partially to completely obscured. Such layers commonly separate others with different crystal habits and the carbonate within and adjacent to the impurity-rich layers commonly has an acicular habit.

Type 6. layers are essentially inclusion-free and occur beiween cther types.

Most growth layers in stalactites are represented by types 1 and 6 , and it is a popular misconception as to the dominance of type 5 layers.

Inclusion-defined layers (types 1-5) may pass into each other laterally or disappear altogether when transitional to type 6 layers. During stalactite growth various layer types give rise to, or alternate with, others.

Some layers are sharply defined. They are the result of abrupt changes in inclusion density or type, whereas other layers possess diffuse bcundaries or are themselves diffuse, being composed of widely-spaced inclusions. Diffuse layers may contain large inclusions that are fluid-filled. They display a marked growth anisotropism (Fig. 9). They are thorn-shaped with abrupt constrictions and bulkous origins, and taper to fine points in the direction of growth of the the host carbonate crystal. A complete gradation apparently exists between large and the more common smaller, spindle-shaped inclusions. Both may occur in the same growth layer. Occasionally thin bands of pseudo-pleochroic calcite occur in regions between large inclusions and reveal the existance of former crystal terminations (type 3 growth layers). Such terminations indicate that the calcite between the larger inclusions grew as individual small crystals and provide 


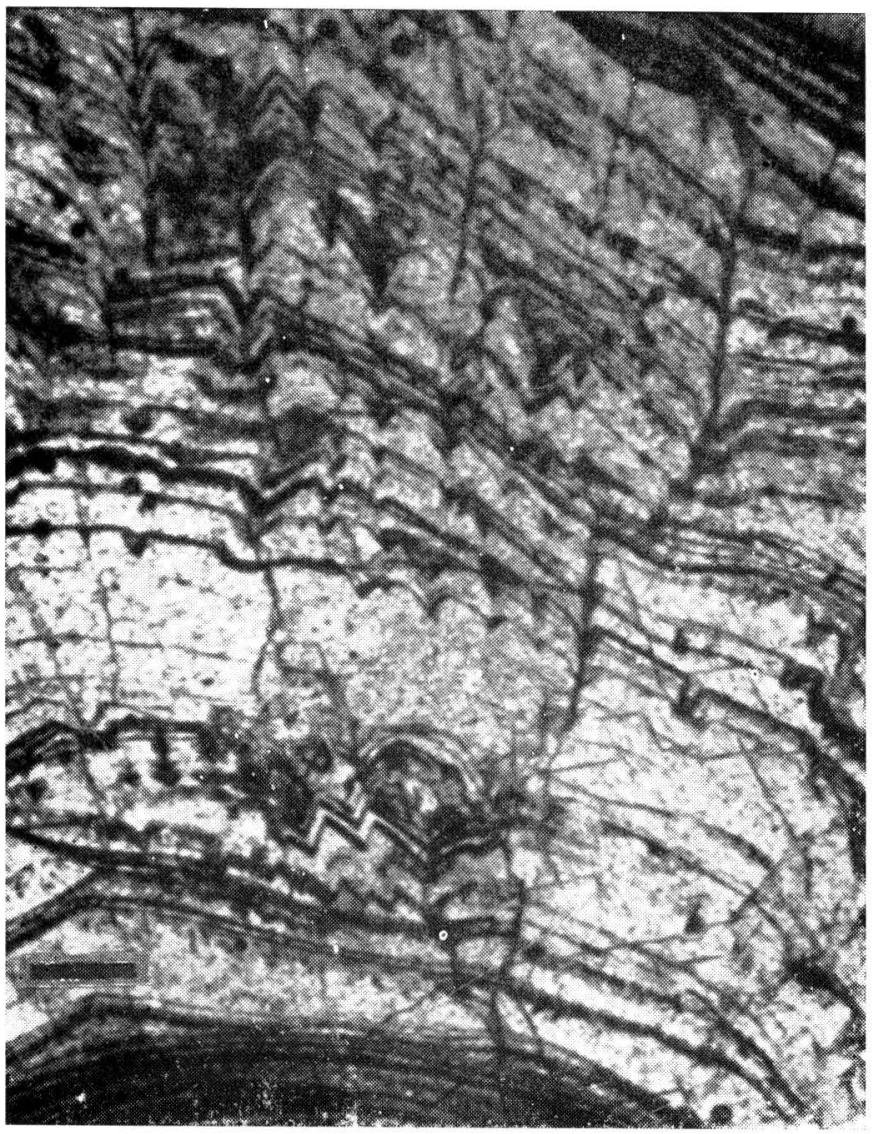

Fig. 7 - Stalactite section characterized by many pseudo-pleochroic and ama!! inclusion defined growth lavers defining former truncated calcite crystal terminations. Plane polarized light. Scale is $0.5 \mathrm{~mm}$.

evidence for an interpretation of linear inclusions as modified inter-acicular crystal spaces and for the proposal that the columnar calcite crystals have arisen from an earlier acicular precursor.

Scanning electron microscope examination of fractured surfaces revealed no identifiable foreign material in locations known to contain abundant inclusions (Kendall and Broughton, 1978). Instead, the inclusion-rich layers appear as a series of mutually-interfering, spindle-shaped depressions that are interpreted as walls of markedly-elongate pores. The traces of linear inclusions exhibit a marked regularity in size and spacing 
(Fig. 10). In sections cut normal to the crystal's c-axis, these pores are seen in cross-section and appear as triangular holes with concave sides.

These observations suggest that most inclusions must be fluid-filled microcavities. Many of these in thin-sections so disperse light as to impart a false brownish colouration and pseudopleochroism to the calcite. Etching inclusion-rich stalactitic calcites also commonly fails to yield insoluble residue.

\section{ORIGIN OF COLUMNAR CRYSTALS IN STALACTITIC CARBONATE}

This research proposes an interpretation for the growth of stalactitic carbonate that involves the development of nume-

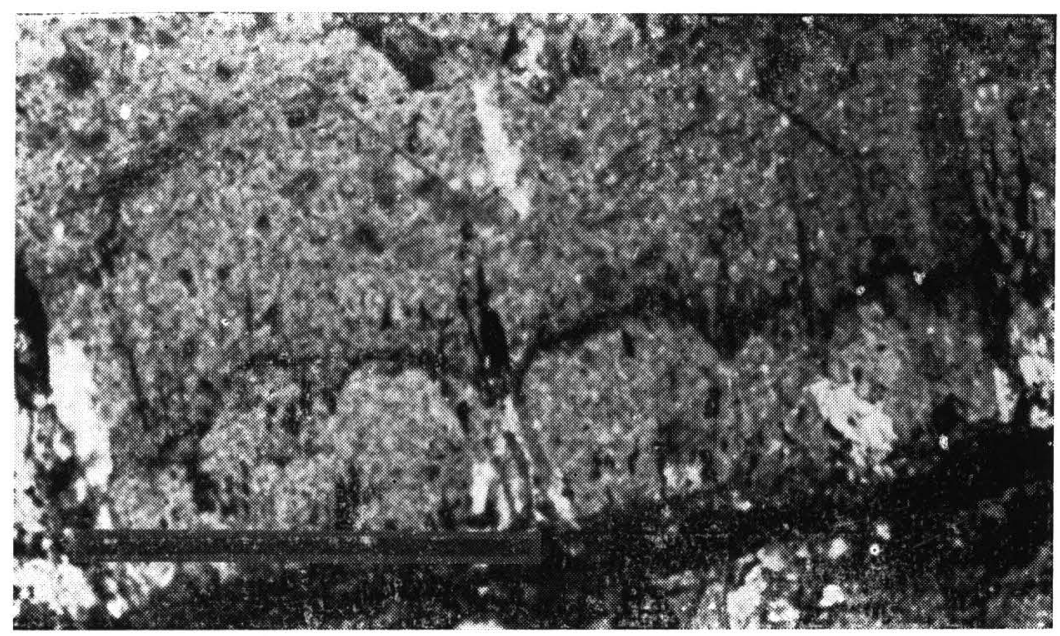

Fig. 8 - Pseudo-pleochroic calcite defining former positions of calcite crystal terminations within a larger crystal. Cross-polarized light. Scale is $0.5 \mathrm{~mm}$.

rous small syntaxial overgrowth crystallites on the growing surfaces of the columnar crystals. These crystallites partially coalesce during growth to generate the large columnar crystals without there being any intermediary acicular phase. This is a secondary phenomenon, nevertheless, in the sense that the columnar crystals are not entities at the growing surface and arise by the amalgamation of much smaller crystallites. The columnar crystals have a crystallite precursor in lattics continuity with the underlying columnar crystals. 

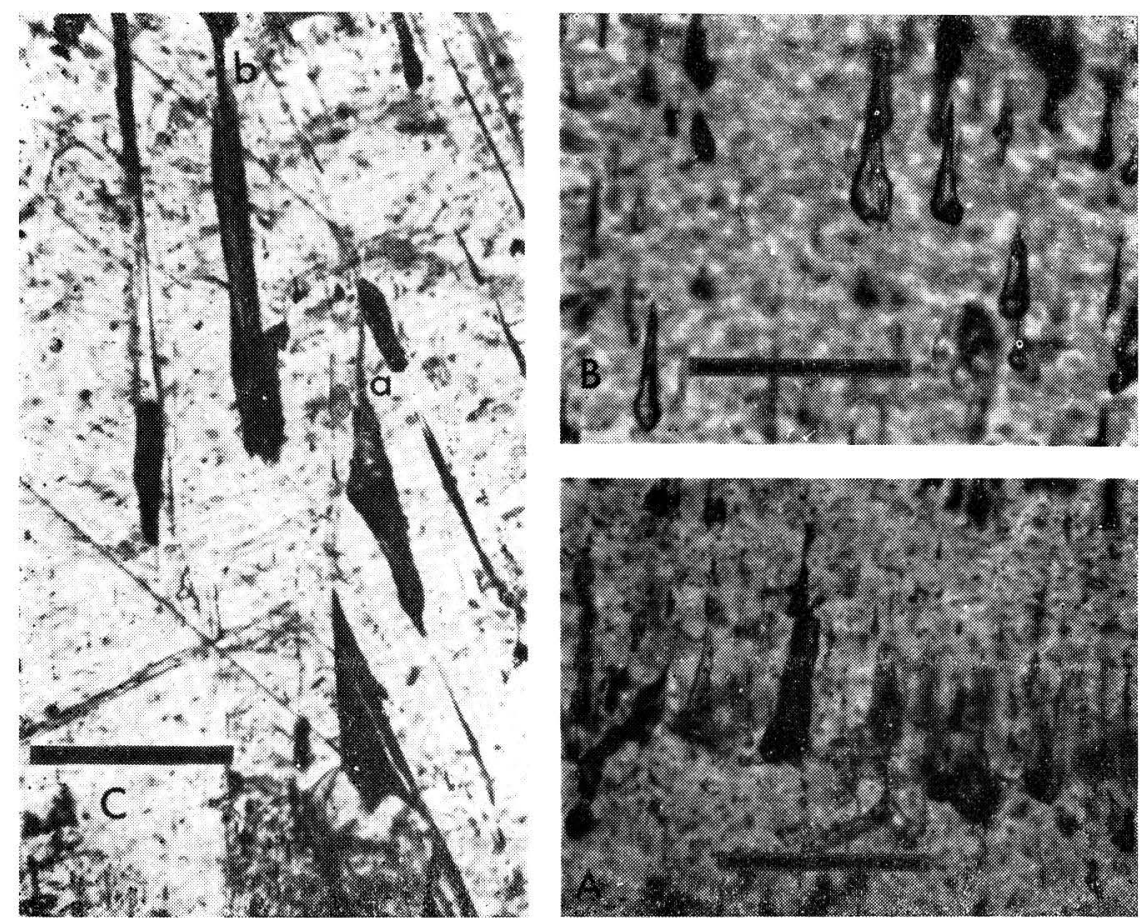

Fig. 9 - Fluid-filled inclusions.

A. Concentration of inclusions that define a growth layer.

B. Inclusions with a marked growth anisotropism restricted towards the direction of growth.

C. Inclusion orientation and boundary conditions between two differently oriented host crystals. Inclusion no. $a$ in the right-hand crystal is truncated by the growth of the left-hand crystal, whereas at inclusion no. $b$, the situation is reversed.

Plane polarized light. Scales ore $1.0 \mathrm{~mm}$.

The next section discriminates between this concept and an origin that involves an acicular carbonate precursor that recrystallizes to form large columnar calcite crystals. This growth mechanism is common to many marine cements that have been recently interpreted as replacements after an acicular carkonate (Kendall, 1976, 1977; Kendall and Tucker, 1973).

\section{Nature of the Multicrystalline Precursor}

Evidence for the secondary nature of most stalactitic carbonate from a multicrystalline syntaxial precursor includes: 

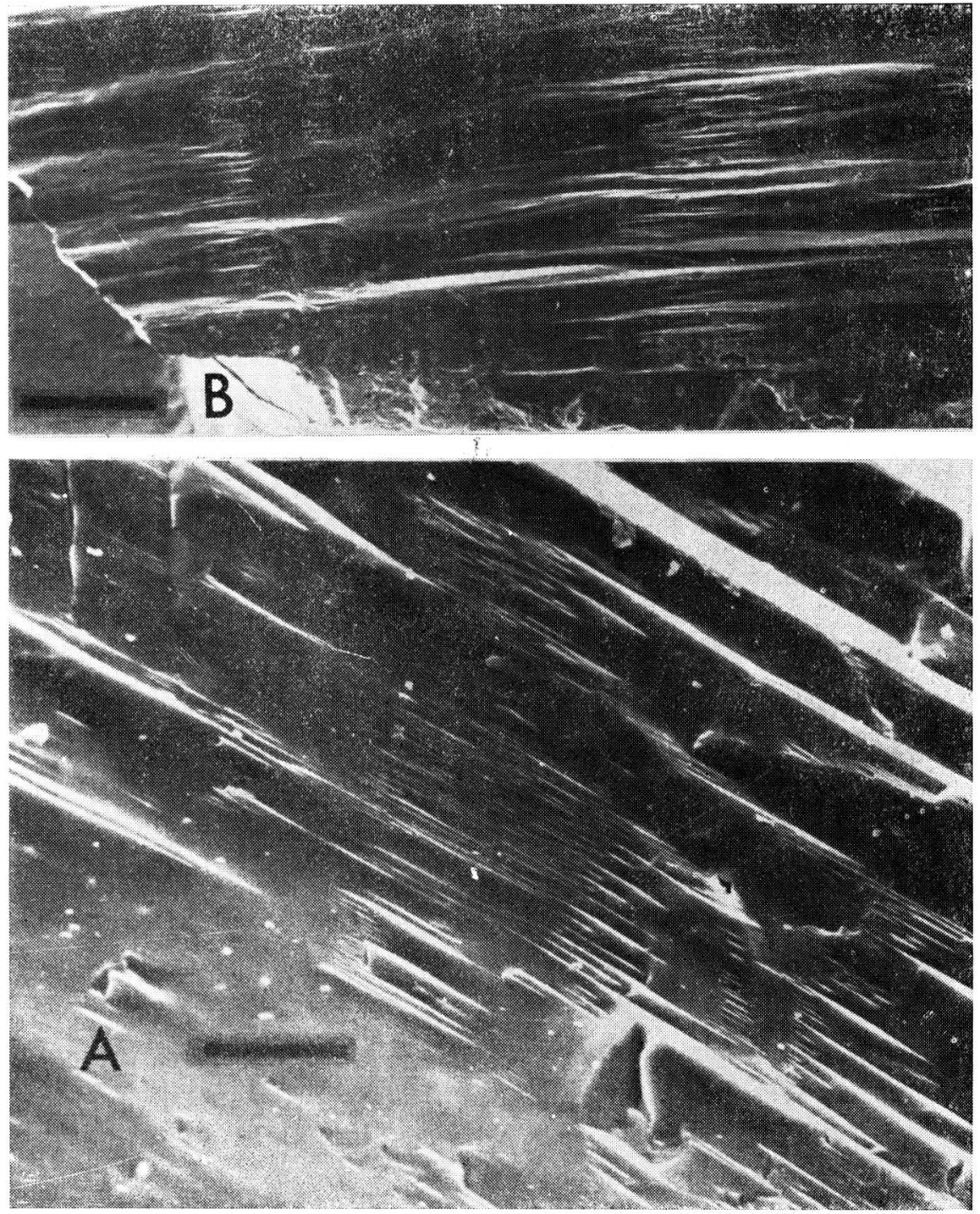

Fig. 10 - Two fracture surfaces of columnar calcite crystals showing inclusion traces that appear as spindle-shaped depressions and linear striations. These are interpreted as the remnant spaces between partially coalesced crystallites, and their mergence into larger crystals. Note the regularity and spacing that define a growth layer. Scanning electron micrcgraphs. Scales are 20 microns (A) and 500 microns (B). 
1. The almost ubiquitous occurrence of linear inclusions.

2. Occurrence of inclusion-defined crystal terminations between some large linear inclusions. This suggests that discrete entities, as acicular crystals or individual crystallite overgrowths, combined to generate the larger columnar crystals.

3. Presence of acicular calcite layers that pass gradually into layers composed of columnar calcite crystals enveloping linear inclusions (Fig. 11). This is not a partial replacement of an acicular precursor, because in most actively growing stalactites the columnar crystals commonly extend all the way to the growing surface. If columnar crystals are indeed secondary, as proposed, they must be generated almost immediately after carbonate precipitation behind the growth surface. There is no room for any acicular precursor.

Inclusion-defined growth layers which delineate former crystal terminations (type 4) cannot be explained by any process involving replacement of an acicular precursor. This type of growth layer is most readily explained where an existing columnar crystal with planar terminal faces splits into numerous, similarly-oriented (syntaxial) crystallite overgrowths, perhaps as a result of impurity absorption. Water trapped between these crystallites would then give rise to the linear inclusions. Later, lateral crystallite growth would cause their partial coalescence and the regeneration of the large columnar calcite crystals.

The large crystal that forms from the partial to complete coalescence of syntaxial crystallites is a secondary or polycrystal, and must not be confused with any neomorphic process. Since the crystallites commonly fail to completely coalesce (hence inclusion defined growth layers), stalactitic carbo nate crystals are a type of skeletal crystal aggregate.

Syntaxial Crystallite Coalescences and Mergence During Growth

The pores revealed by scanning electron microscopy are interpreted as vestiges of former inter-crystallite spaces that remain following partial crystallite coalescence. The triangular cross-sections suggest that crystallites were hexagonally arranged on the growth surface and each pore results from lateral growth of three adjacent crystallites. The regular pattern of inclusion lineations seen in many growth layers appears to result from a process of crystallite mergence and overlap.

In addition to forming larger crystals by a process of lateral crystallite growth immediately behind the growing surface. the crystals may also merge to generate larger growing units. This process is similar to that on the growth surface of echinoderm 


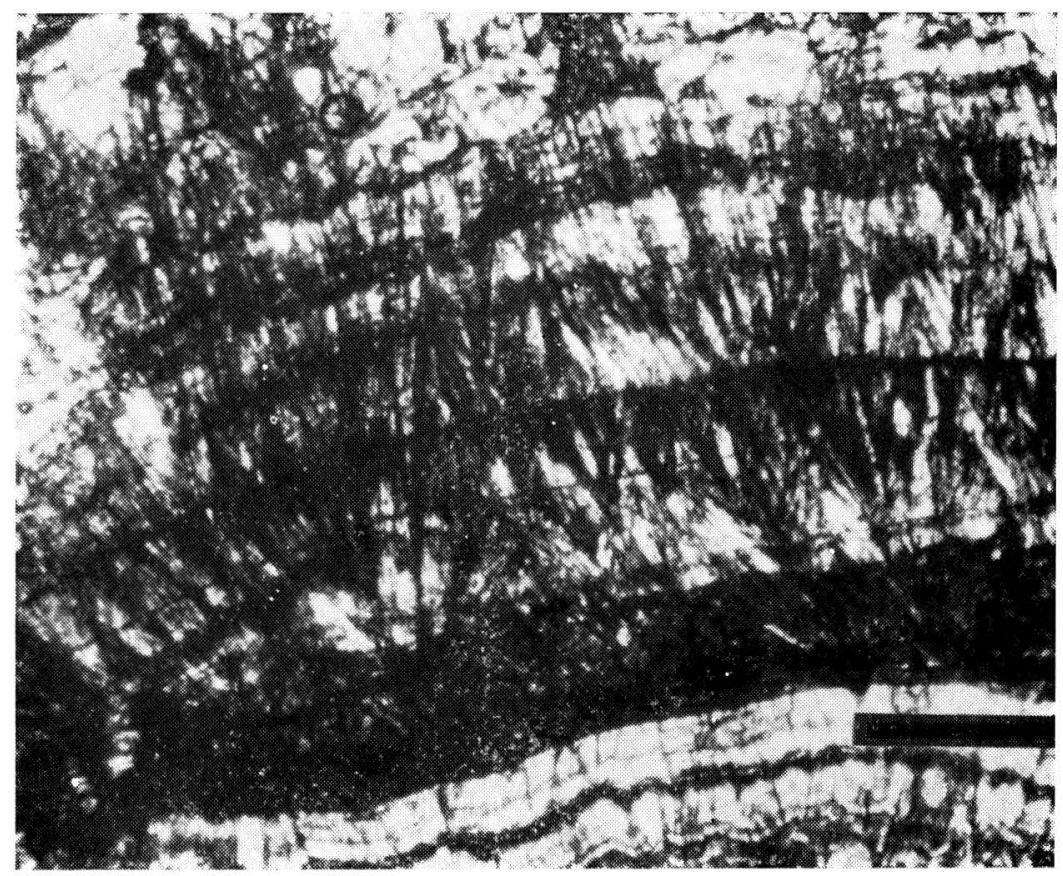

Fig. 11 - Layers of acicular calcite passing gradually into layers of colu mnar calcite with lincar inclusions. Plane polarized light. Scale is $0.5 \mathrm{~mm}$.

grains and quartz overgrowths. Figure 10 illustrates a stalactite growth layer in which crystallite coalescence then mergence is suggested. Such a layer is characterized by a series of striations (traces of linear inclusions) that exhibit a regularity in the spacing of similarly-sized striations, a proportional relationship between striation-length and spacing and a regularity in the position at which striations of similar length disappear. Such striations are interpreted to record the traces of, and eventual disappearance of, former positions of crystallite boundaries. This supports the mergence of crystallites and small crystals into larger where demonstrated by the occurrence within columnar crystals of smaller inclusion-defined crystal boundaries.

Crystallite mergence into larger units, subsequent to normal syntaxial coalescence, is apparently only a temporary phase of stalactite growth. There is no evidence of it in most growth layers. 


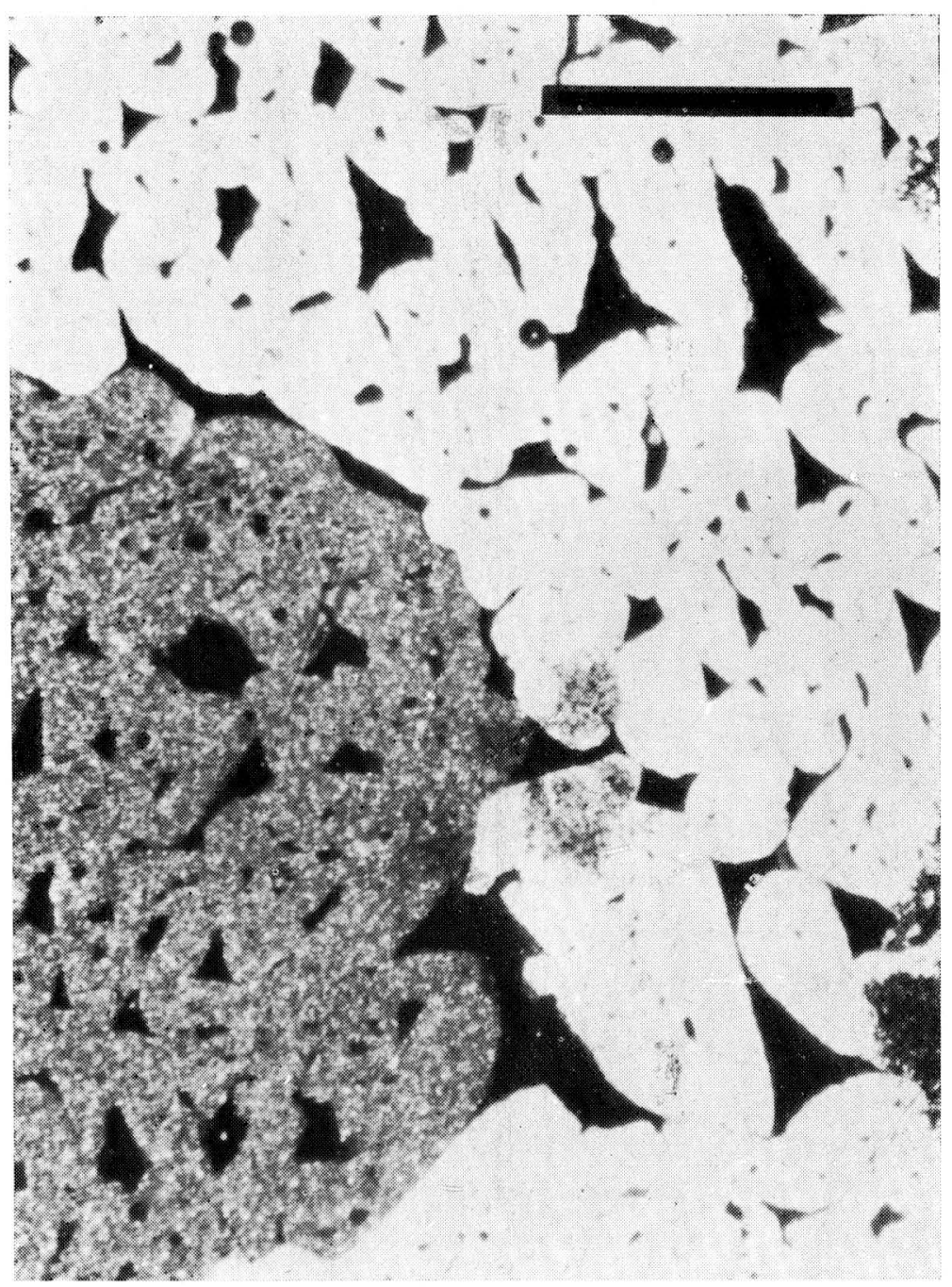

Fig. 12 - Cross-section of partially coalesced crystals with triangular sections representative of soda-straw infilling. The generation of triangular pores are the remnants of former inter-crystallite spaces. Cross-polarized light. Scale is $1.0 \mathrm{~mm}$. 
Similar, but much larger elongate pores (elongate parallel to the host crystal c-axes) with triangular cross-sections are comminly present in calcite that infills the central canals in «soda-straw» stalactices. The infilling of this structure is recognized as beginning with the growth of numerous separate, but similarly-oriented, trigonal crystals. During carbonate precipitation, they coalesce to form large polycrystals that contain elongate pores. These are remnanis cf the former intercrystallite spaces, but on a scale larger than commonly characterizing normal radial columnar stalactitic growth. See Figure 12.

Direct evidence for a multicrystalline (crystallite) precursor comes from the examination of growing stalactite surfaces. Although many are smooth, others are rough to the touch. Roughness is due to the occurrence cf a multitude of small projections, the larger of which possess crystal faces. These faces indicate that the projections are a growth form. Where thick impurityrich layers overlie layers composed of columnar crystals the ccntact is commonly finely-denticulate suggesting preservation of the crystallite growth form. The projections along the contact are spaced and oriented similarly to linear inclusions in the underlying calcite crystals. Such projections, frequently with crystal iaces, are a growth form and not originating from solutional fretting.

\section{ORIGIN OF STALACTITIC CRYSTAL FABRICS}

Stalactitic growth may be pictured as a sequence of growth events and the surface morphology during each determined by the environment of that episode. During some episodes the surface is composed of innumerable crystallites which coalesce immediately behind the growing surface to generate the columnar crystals. Perfect coalescence or the obliteration of all intercrystallite space by lateral crystallite growth produces inclusion-free calcite layers, whereas less perfect coalescence allowing entrapment of water between crystallites generates linear inclusion-bearing calcite layers. This coalescence is possible because each crystallite is a syntaxial overgrowth of the same crystal as its neighbors. Thus, neighbouring crystallites possess near-identical lattice orientation and can coalesce or combine into a single crystal.

At other periods, the crystallite form is no longer stable and mergence of crystals on the growing surface results in the formation of larger crystallites and, eventually, of undivided crystals with planar crystal faces. Calcite deposited on these crystal iaces would also be inclusion-free. During yet other episodes, no crystallite coalescence occurs and the deposited carbo- 
nate assumes an acicular habit. Numerous changes in the environmental conditions that cause variations in the perfection of crystallite lateral growth (coalescence) or mergence are considered to be responsible for the pronounced growth layering that characterizes most stalactite draperies. The passage of acicular habit crystals into normal columnar growth layers results from variation in the degree of overgrowth crystallite coalescence with time (Fig. 11). This is, undoubtedly related to the change in water flow, the most variable factor in the cave envircnment.

Crystal boundaries in stalactitic carbonate are thus interpreted not as the consequence of the crystals themselves interacting, but related to the precursor syntaxial crystallite overgrowths on the columnar crystals. Each columnar crystal's growth surface is characterized by numerous crystallite terminations. Later coalescence must of necessity be a compromise between them giving a jagged, serrated or otherwise nonplanar boundary. This is partially dependant upon the degree of lateral lattice continuity $\mathrm{cn}$ a curved growth surface (Broughtion, 1977). The degree of lattice mismatch may be sufficient to favour subcrystals.

Thrailkill (1976) attributes the entire columnar crystal fabric to neomorphism or recrystallization products. The patchy developed fabric can be easily mistaken for neomorphism characterized by gradual boundaries that occur between the various types of calcite mcsaic (Bathhurst, 1971). This is easily explained by the success of the crystallite coalescence laterally across a curved growth surface relative to the lattice continuity.

\section{DISCUSSION}

\section{Influence of Water-Film on Crystal Fabric and Stalactite Stability}

The numerous changes in environmental conditions on the growth surface of stalactites, especially water flow rates and film thickness, cause variations in the perfection of lateral crystallite coalescence and in the stability of the resulting growth form. These in turn would tend to favour the continuity of one growth layer type over another.

Kendall and Broughton (1978) suggest that crystal growth on the stalactite and stalagmite surfaces favours multiple crystallite habits because of the thin water films.

The cylindrical to cone-shaped form of most stalactites is clearly that which sheds water most rapidly. The form is thus 
a product and a function of an interaction of gravitational attraction with some of the properties of water, particularly surface tension. If large crystal terminations were developed on stalactite surfaces this would cause significant departures from the optimum water-shedding form. Water would be diverted around the crystal termination and its growth would be inhibited relative to other parts of the surface. As a consequence such projections would gradually be suppressed. Crystals with large terminal faces upon stalactites appear to develop only during immersion, as during episodes of cave flooding.

It is possible that the water film thickness governs the size of crystallites on the growing surfaces of stalactites. When films are thin, only the smaller crystallites will be stable because larger forms would disturb the thin flow of water. With increasing film thickness, however, it is to be expected that larger crystallites could be formed (by mergence or amalgamation of the smaller) without water film disturbance.

Furthermore, a growth surface of numerous rational crystal faces (crystallites) would lower the surface energy. Smooth surfaces are to be expected when surface tension in the water film is paramount. Such a smooth surface would, in effect, consist of innumerable minute, high-energy vicinal and irrational crystal faces. On the other hand, smooth surface specimens are known, but may record episodes of calcite precipitation characterized by pseudo-pleochroic growth layers (type 2 layers).

Orderly crystallite growth may be frequently inhibited by adhesion of gas bubbles on the growing surface. This results in bubbles that became set within tubular cavities and form thorn-shaped fluid-filled inclusions when the enveloped by precipitated carbonate. This speculation would imply that the stalactite surface episodically became dry such that the returning water film was unable to completely wet the surface. Most inclusions do not form this way.

\section{CONCLUSIONS}

The crystals in stalactites composed of radial-columnar calcite did not interact at growing surfaces. Consequently crystal fabrics within such stalactites do not, for the most part, exhibit evidence of competitive crystal growth. However, during episodes of cave flooding, crystal fabrics resembling those of drusy cements may develop.

The columnar crystals result from a coalescence immediately behind the growing surface of numerous syntaxial crystal- 
lite overgrowths. The columnar calcite crystals do not interfere with each other's growth as individuals at the growing surfaces as in competitive growth. Incomplete lateral crystallite coalescence gives rise to fluid-filled lines: $r$ microcavities. In the absence of crystallite coalescence, acicular crystals are formed.

Ii is beileved that the crystallite growth morphology is favoured and perpetuated because of carbcnate precipitation taking place from thin water fiims. Large crystal terminations are suppressed because of slower growth when the flow of water is diverted away from the projection. This would be only successful during episcdes of cave flooding. Conversely, perfectly smooth growth surfaces are not favoured because surface-energy considerations pracipitate carbonate on lower energy crystallite faces.

Variations in water film thickness are suggested to possibly cause changes in the stability of morphologies developed on the growth surfaces. and thus alterations in the type of crystal mosaic deposited.

\section{ACKNOWLEDGMENTS}

This paper is based on research collaboration with A.C. Kendall, presently at Amoco Canada Petroleum Company, Calgary, Alberta. Much of this research into the origin of marine and vadose cements has been published as Kendall and Broughton $(1977,1978)$. This paper is restricted to the aspects of our collaboration that focus on material relevant to a speleologicallyoriented reader.

Thanks is expressed to many members of the National Speleological Society (Huntsville, Alabama), many of whom wish to remain anonymous, for providing the specimens upon wich this study was based. Most specimens submitted came from existing collections.

Research faclities were provided over a five year period by the Department of Mineral Resources, Subsurface Geology Laboratory, Regina and the Department of Geology, University of Cambridge. Scanning electron microscope facilities were provided by the Department of Entomology at the University of Alberta, Edmonton. The several earlier versions of this and related manuscripts ware critically reviewed by Drs. J.E. Cristopher, C.E. Dunn and D.F. Paterson of the Department of Mineral Resources, Regina; Dr. R.G.C. Bathhurst of the University of Liverpool; Dr. J.A. Dickson of the University of Nottingham and Prof. R.L. Folk of the University of Texas, Austin.

\section{RESUME'}

Les surfaces de croissance de la plupart des stalactites et des stalagmites sont interprétées comme étant constituées de nombreuses cristallites à recouvrement syntaxial. Celles-ci s'unissent immédiatement derrière la surface de croissance, entermant souvent des portions du film d'eau sous forme de cavités à contenu liquide. Les inculsions liquides représentent des espaces entre les cristallites anciens et caractérisent ce qui a été très mal in- 
terprété comme étant des "anneaux de croissance». La coalescence complète des cristallites engendre de la calcite dépourvue d'inclusions, tandis que l'inhibition de la coalescence latérale des cristallites de recouvrement forme de couches de calcite aciculaire. Généralement ce n'est que pendant les périodes où les grottes sont inondées que les cristallites se soudent et se recouvrent ls unes les autres, la précipitation n'apparaissant éventuallement que sur les grandes faces planes des cristaux. La croissance du carbonate des stalactites est secondaire elle se fait à partir d'un précurseur multi-cristallin qui est, en quelque sorte, un gros cristal qui sert de squelette. Les cristallites précurseurs forment un treillis qui est en continuité avec le substrat et avec les cristallites adjacent. Les limites entre cristaux proviennent de la mauvais soudure des bords du treillis sur la surface de croissance courbée. Il n'y a pas de croissance compétitive puisque les cristaux secondaires en forme de colonnes n'interfèrent pas les uns avec les autres.

\section{REFERENCES}

BATHHURST, R.GC., 1971. Carbonate Sediments anr their Diagenesis. Developments in Sedimentology 12, Elsevier, Amsterdam, $620 \mathrm{p}$.

BROUGHTON, P.L., 1977. Crystallite precursors and the genesis of irregular crystal boundaries in radial fibrous carbonate fabrics. In T.D. Ford (editor), Proc. 7th International Speleological Congr., Sheffield 1977, p. 84-86.

BUCKLEY, H.E., 1951. Crystal Growth. Wiley, New York, N.Y., 571 p

FOLK, R.L. and ASSERETO, R. 1976. Comparative fabrics of length-slow and length-fast calcite and calcitized aragonite in a Holocene speleoth ${ }^{\prime}$ Carlsbad Caverns, New Mexico. Jour. Sed. Petrology, 46:486-496.

HAHNE C., KIRCHMAYER, M. and OTTENMENN, J., 1968. *Holenperlen* (Cave Pearls) besonders aus Bergwerken des Ruhrgebietes Modellfalle zum Studium diagenetischer Vorange an Einzelooiden. Neues Jahrb. Geol. Palaontol. Abbandl., 130:1-46.

KENDALL, A.C., 1976. Origin of fibrous calcites that apparently replace foraminiferal tests. Jour. Sed. Petrology, 46:545-547.

KENDALL, A.C., 1977. Fascicular-optic calcite: a replacement after bundred acicular carbonate cement. Jour. Sed. Petrology, 47:1056-1062.

KENDALL, A.C. and BROUGHTON, P.L., 1977. Discussion: calcite and aragonite fabrics Carlsbad Caverns, by R.L. Folk and R. Assereto (Jour. Sed. Petrology, 46:486-496). Jour. Sed. Petrology, 47:1397-1400.

KENDALL, A.C. and BROUGHTON, P.L., 1978. Origin of fabrics in speleo thems composed of columnar calcite crystals. Jour. Sed. Petrology. 48:519-538.

KENDALL, A.C. and TUCKER, M.E., 1973. Radiaxial fibrous calcite: a replacement after acicular carbonate. Sedimentology, 20:365-389.

KENDALL, A.C. and KIRCHMAYER, M. 1964. Hohlemperlen (Cave Pearls, perles de cavernes) Vorkommen, Definition sowie strukturelle Beziehung zu ahnlichen Sedimentsphariten. Oesterr. Akad Wiss. Math. Naturw. Kl., Anx., 10:223-229.

MOORE, G.W., 1962. The growth of stalactites. Bull. Natl. Speleol. Soc., 24:95-106.

PRINZ, A. 1906. Les cristallisations des grottes de Belgique. Nouv. Mem. Soc. Belge. Geol.., p. 1-90.

THRAILKILL, J., 1876, Speleothems. In M.R. Walter (editor.), Stromatolites (Developments in Sedimentology 20), Elsevier, Amsterdam, p. 73-86. 